\title{
MacBride on Truth in Truthmaking
}

Matthew Simpson

\section{Introduction}

Fraser MacBride (2013) argues that if deflationism about truth is right, then the truthmaker principle that every truth has a truthmaker is implausible. He claims that given deflationism, the truthmaker principle is equivalent to a certain infinite conjunction which is itself implausible, because there is no independent reason to believe in its conjuncts. But this leaves no motivation for adopting the truthmaker principle at all, if deflationism is true. So anyone interested in accepting the truthmaker principle had better reject deflationism.

In this paper I argue that MacBride's argument fails: even if deflationism is true, the truthmaker principle is not equivalent to the implausible conjunction. Instead, the deflationist can give a different reading of the truthmaker principle on which the principle is not a mere abbreviation of the implausible conjunction, and is independently motivated. The truthmaker sceptic may of course doubt these motivations; but this is beside the point, for my argument only intends to show that deflationism has no bearing on the plausibility of these motivations.

\section{The Argument}


MacBride makes many points in his paper, but his central argument is as follows. Following Lewis (2001: 278-279), if deflationism is true then the truthmaker principle (hereafter TMP) that every truth has a truthmaker is just a short version of the following infinitely long conjunction:

(1) (It's true that cats purr iff there exists something whose existence entails that cats purr) and (it's true that dogs bark iff there exists something whose existence entails that dogs bark) and ...

which given biconditionals of the form

(2) It's true that cats purr iff cats purr

is no more than this infinite conjunction:

(C) (Cats purr iff there exists something whose existence entails that cats purr) and (dogs bark iff there exists something whose existence entails that dogs bark) and ...

The only role truth plays in TMP is to abbreviate $(C)$ in order to state it finitely. From there, MacBride argues that if TMP is a mere abbreviation of (C), it cannot be any more plausible than (C), in the sense that our reasons for believing it cannot extend beyond our reasons for believing (C). But, MacBride argues, since (C) is a conjunction there's no more reason to believe it than whatever reason we have to believe its conjuncts, and he makes a separate argument (2013: 4-5) that there's 
no reason to believe in the conjuncts in the first place. So (C) and therefore TMP are implausible, in the sense that we have no reason to believe them, if deflationism is true. A supporter of TMP should reject deflationism, or else she has to admit that we've no reason to believe her favoured principle.

The general reason for this result, according to MacBride, is that on a deflationary reading, TMP embodies no content beyond (C) and admits of no independent motivation. (C) and TMP are just notational variants of one another. The problem here isn't that the deflationist's truthmaker principle entails (C). Any truthmaker principle will do that. The problem is that the deflationist has no other source of motivation for TMP than the conjuncts of (C). By contrast consider a correspondence theory of truth which takes truth to consist in some kind of relation between propositions and reality. Such a theory gives TMP independent motivation - TMP would flow naturally from general considerations about the nature of truth. But such considerations are unavailable to a deflationist who denies that truth is 'any kind of relation whatsoever' (p.2) and merely offers the redundancy biconditionals like (2). Given a correspondence theory we have independent reason to believe (C) which, MacBride allows (2013: 7), might ground replies to his arguments about the implausibility of (C)'s conjuncts. But a deflationist has no such independent reason, and so has no grounds from which to argue this. So deflationism renders TMP implausible. 
At this point a wily deflationary truthmaker theorist might try to escape MacBride's argument by rejecting the unrestricted truthmaker principle that every truth has a truthmaker, and instead accepting a restricted principle that only certain truths have them. For instance a truthmaker non-maximalist (see e.g. Simons 2005; Mellor 2009) might choose a class of truths he calls 'primary' and say that only these primary truths have truthmakers. But this won't necessarily work, for MacBride can just run his argument again, replacing the unrestricted truthmaker principle with the restricted one. In any case, I will argue that MacBride's argument fails whichever of these truthmaker principles is considered.

\section{Readings of the Truthmaker Principle}

MacBride's crucial claim is that if deflationism is true, the truthmaker principle is just an abbreviation of (C), no more than a notational variant of it. But this claim is false. For it is a mistake to take, as MacBride and Lewis do, an instance of TMP to look like:

(3) It is true that $p$ iff there exists something whose existence entails that $p$

which then ends up being generalised via conjunction to make $(C)$ as we saw above. Instead, an instance looks like this:

(4) $\langle p>$ is true iff $\langle p>$ has a truthmaker 
and the corresponding generalisation corresponding to this is not $(C)$ but:

(5) For every proposition $\langle p\rangle,\langle p\rangle$ is true iff $\langle p\rangle$ has a truthmaker

There are two crucial differences between (3) and (C) on the one hand and (4) and (5) on the other. First, the latter pair mention propositions and use the truth predicate '... is true', but the former don't, and instead use the truth operator 'it is true that ...'. Second, (C) is a conjunction of instances of the form (3), but (5) is a universal quantification of (4). But why should these technical differences matter?

They matter because the mention of propositions and the appearance of the quantifier in (5) are the result of the central motivation behind truthmaker theory. There is good reason to think that the primary reason for believing in truthmakers does not concern the nature of truth but the nature of truthbearers like propositions. ${ }^{1}$ The truthmaker principle should then reflect this. The basic idea is that since not all propositions are true, we need truthmakers to account for the difference between those which are true and those which are not. Propositions aren't just true. This idea is often put in more abstract terms like 'truth is grounded in reality' (Rodriguez-Pereyra, 2006, 186). But really it seems that the motivation is about propositions: propositions are things which can be and often are false, so we need an account of why the true ones are true. The fact that some propositions aren't true is a fact about propositions, not a fact about truth.

\footnotetext{
${ }^{1}$ In the case of (5) the truthbearers are propositions, but the idea applies to other truthbearers too. I will focus on propositions for simplicity.
} 
This importance of facts about propositions already gives us reason to focus on claims like (5) rather than (C), since the former but not the latter mention propositions, and hence explicitly display the core ideas behind truthmaker theory. Not mentioning truthbearers simply changes the subject. ${ }^{2}$ Indeed, the 'redundancy biconditionals' MacBride cites - which use the truth operator and are of the form 'It is true that $p$ iff $p$ ' - are not even the ones that deflationists like Horwich take to be the central biconditionals in a theory of truth. Those biconditionals instead employ the truth predicate and mention propositions, and are of the form ' $<p>$ is true iff $p^{\prime}$, or in the case of sentential deflationists employ the truth predicate and mention sentences: ' $p$ ' is true iff $p$ '. So the focus on claims like (1), (2), and (C), is a mistake, because deflationists are interested in a different set of claims than these.

But can a deflationist really accept the above reasons for believing in truthmakers? I see no reason why not. All she needs to do is show that she can make sense of a claim like 'propositions aren't just true' without invoking truth. But deflationists often face this kind of challenge: explain general claims involving 'truth' or 'true', without invoking truth (see e.g. Horwich 1998: ch.3). The most appealing strategy would be to express the core truthmaker motivation like so:

(6) That <cats purr > exists doesn't entail that cats purr

\footnotetext{
${ }^{2}$ An objection: is this mere speculation about the thoughts of truthmaker theorists? I don't think so - but even if it is, the deflationist can still adopt this argument for truthmaker theory, whether or not other truthmaker theorists will agree with her.
} 
This doesn't mention truth. As in other cases, it shows the deflationist's attempt to understand a general claim about truth in terms of a general claim about something else, in this case truthbearers.

Two comments are in order. First, (6) clearly is not a general principle but a particular claim about one proposition. To make it general, we need to invoke a suitable generalisation strategy which I will outline in the next section. Second, one may have qualms about the existence of propositions. However, these qualms are really nothing to do with deflationism. They simply depend on what you think propositions are. If you are happy with talking about them existing, merely accept the above. If you are not, and you prefer to think of a proposition as just being what a sentence means, you can rewrite the above as something like:

(7) That a sentence $s$ means that cats purr, doesn't entail that cats purr.

In any case, the only problem for the deflationist here is whether she can make sense of propositions. It's well known that this is a tricky issue. But MacBride isn't discussing the adequacy of deflationism, but the compatibility of deflationism with the truthmaker principle, so it makes no difference to the issue at hand. The only important point here is that the deflationist can make sense of the idea that there 
are false truthbearers; and it seems likely that she can, whether or not she needs to appeal to propositions to do so. ${ }^{3}$

So we've seen that the deflationist can argue for the truthmaker principle on the basis of facts about propositions rather than truth, and that these arguments are perfectly compatible with deflationism. But this route is utterly invisible if, as MacBride does, we only focus on claims like (3) and (C), because these claims only use the truth operator 'It is true that ...' and so don't mention truthbearers at all. So we've established the first reason for preferring (5) over (C).

\section{Conjunctions and Generalisations}

The second reason for preferring (5) is that it is a universal generalisation whereas (C) is an infinite conjunction. This is a good reason for preferring (5) because it reflects the fact that the central motivation for truthmaker theory discussed in the last section is a general thought about propositions as such, namely that they need truthmakers. It is familiar that universally quantified propositions are not expressed by infinite conjunctions. An infinite conjunction of the form ' $a$ is $F$ and $b$ is $F$ and ...' does not entail the corresponding universal generalisation 'Every $x$ is $F$ ' because it does not itself entail that there isn't some further entity $z$, not mentioned in the infinite conjunction, which isn't $F$. What it needs is the so-called 'that's all' clause,

\footnotetext{
${ }^{3}$ That deflationists can make claims about truthbearers like propositions is obscured by the fact that deflationists typically discuss propositions in the context of the equivalence schema ' $\langle p>$ is true iff $p$ ' which they usually use to eliminate the notion of truth, and hence of the proposition. But no such elimination occurs in the case of ' $<p>$ exists'. Indeed there are many contexts in which we talk about propositions without ascribing truth to them - consider for example 'All of the propositions expressed by Tim were complicated'.
} 
which says that there is nothing else in the domain other than $a, b$, and so on. This can be expressed by the sentence 'For all $x, x$ is $a$ or $x$ is $b$, or ...' which will itself be infinitely long. However, (C) is an infinite conjunction without a 'that's all' clause, and so doesn't rule out a claim of the form ' $p$ but there's nothing whose existence entails that $p^{\prime}$, which would be a clear counterexample to the truthmaker principle. (5), on the other hand, does rule this out, because it uses a universal quantifier. So (5) makes a truly general claim about propositions as such, but (C) doesn't, and so the deflationist should choose the former not the latter.

This point may raise eyebrows, because critics (e.g. Gupta 1993) have accused deflationists of not being able to handle universal generalisations involving truth, instead erroneously offering infinite conjunctions. One of the reasons this is so tricky is that a claim like (5) involves a truth-ascription which cannot be eliminated. If we do eliminate the ascription we either get an appearance of a singular term ' $<p>$ ' which has no predicate attached, rendering the claim ungrammatical:

(8) For every proposition $\langle p\rangle,\langle p\rangle$ iff $\langle p\rangle$ has a truthmaker

To fix this we could remove the angle brackets:

(9) For every proposition $\langle p\rangle, p$ iff $\langle p\rangle$ has a truthmaker

But this leaves ' $p$ ' unbound, since the quantifier at the beginning ranges over singular terms (namely, ones which refer to propositions) not over sentence letters. 
This is unacceptable. So it may seem that by insisting on adopting a universal quantification, the deflationist has shot herself in the foot.

There are two responses available here. One is to adopt Wolfgang Künne's approach to truth (Künne 2003: 337) and use sentential quantification to read (5) as:

(10) $\forall p(p$ iff $<p>$ has a truthmaker)

The deflationist would then argue for the admissibility of this form of quantification. For brevity I won't discuss this strategy further but instead turn to the other.

The other strategy is to read (5) as an infinite conjunction but add a universal quantification over propositions which rules out there being further propositions which don't satisfy the claim.

$\left(5^{*}\right)(<$ cats purr $>$ is true iff $<$ cats purr $>$ has a truthmaker) and $(<$ dogs bark $>$ is true iff $<$ dogs bark $>$ has a truthmaker) and ... and for any proposition $x$ ( $x=$ $<$ cats purr $>$ or $x=<$ dogs bark $>$ or ...)

This can then be unpacked to get rid of the truth ascriptions and to unpack the predicate '... has a truthmaker' in the usual way: 
$\left(5^{* *}\right)$ (Cats purr iff there exists something whose existence entails that cats purr) and (dogs bark iff there exists something whose existence entails that dogs bark) and ... and for any proposition $x(x=<$ cats purr $>$ or $x=<$ dogs bark $>$ or ...)

Such a principle is amenable to the deflationist and is sufficiently general, since it has the 'that's all' clause.

There are two further comments to make regarding this last claim. Note how the 'that's all' clause, which says that any proposition you can find is one of the ones already covered in the infinite conjunction, reflects the motivation behind truthmaker theory, namely that the need for truthmakers flows from the nature of propositions in general, so that anything which counts as a proposition is to be covered by the truthmaker principle. Second, note that $\left(5^{* *}\right)$ is identical to what we would get if we fixed (C) to make it more general by adding the 'that's all' clause it needs. This is no surprise, since the 'that's all' clause expresses the general motivation for truthmaker theory which is missing from (C) itself. It's just that (5) makes all of these points much more plain. ${ }^{4}$

The above two strategies can be used to solve the issue raised in the last section that the claim (6), which the deflationist used to express the idea that not all

\footnotetext{
${ }^{4}$ How do we apply these same points to a restricted truthmaker principle? In the case of the conjunctions $\left(C^{*}\right)$ and $\left(5^{*}\right)$ we just eliminate those conjuncts which concern the truths which don't have truthmakers; in the case of the quantification (5) we restrict the quantification only to the truths which we think do have truthmakers.
} 
truthbearers are true, is particular and not general. We can either apply sentential quantification:

(11) $\forall p$ (that $<p>$ exists doesn't entail that $p$ )

or we can create an infinite conjunction and add a 'that's all' clause:

(12) [(that <cats purr> exists doesn't entail that cats purr) and (that $<$ dogs bark> exists doesn't entail that dogs bark) and ...] and for any proposition $x$ $(x=<$ cats purr $>$ or $x=<$ dogs bark $>$ or $\ldots)$

Either of these offers the deflationist a suitable way of providing her general reason for believing in truthmakers. ${ }^{5}$

So it seems that the deflationist need not offer $(C)$ as her truthmaker principle, but can offer (5) instead. There is one more loose end to tie up here. MacBride (2013: $2,8)$ cites Armstrong's claim that according to deflationism, truth isn't any kind of relation. Surely this general metaphysical claim challenges the very idea of truthmaker theory - if truth is no relation at all, how can true claims be in a relation with their truthmakers? The above discussion has revealed that deflationism has no such impact: the sense in which deflationists reject that truth is a relation is compatible with accepting truthmaker theory. Deflationists will deny that truth can be elucidated or anlaysed as a relation. But the truthmaker principle doesn't need

\footnotetext{
${ }^{5}$ The same method can be applied to the other strategy where we don't mention the existence of propositions but the fact that a sentence $s$ means that $p$.
} 
to be read as an analysis or elucidation of truth. Instead it can be read as a claim about the extension of 'is true' - it applies to all and only those propositions with truthmakers. And deflationists needn't be afraid of making claims about the extension of 'is true,' because claims about the extensions of predicates needn't be analyses of those predicates.

A deflationist can therefore assert the truthmaker principle, albeit for reasons not strictly concerning truth, and on those grounds alone say that truth is (coextensive with) the truthmaking relation in the sense that every true proposition bears the truthmaking relation to its truthmaker. But this doesn't entail that truth can be analysed in terms of truthmaking, any more than the utilitarian claim that 'goodness' is coextensive with 'utility maximising' entails that goodness can be analysed as what maximises utility.

To sum up, deflationism does not render the truthmaker principle implausible. Deflationism doesn't entail that the truthmaker principle is a mere abbreviation of (C). Nor does it entail that there can be no independent motivations for truthmaking, since such motivations don't concern truth but truthbearers, and deflationists can happily talk about truthbearers. So MacBride's argument fails: 
deflationists and non-deflationists alike can, if convinced by truthmaker advocates' arguments, adopt the truthmaker principle. ${ }^{6}$

Robinson College

University of Cambridge

Cambridge

CB3 9AN

UK

matthew.simpson@cantab.net

Abstract

Fraser MacBride has argued that deflationism about truth makes the truthmaker principle, that every truth has a truthmaker, implausible. This is because on a deflationary view, the truthmaker principle is a mere abbreviation of a conjunction of claims which have no independent motivation. In this paper I argue that this claim is false: deflationism does not entail that the truthmaker principle is a mere abbreviation of such a conjunction, because the claims MacBride focuses on are in fact irrelevant to the motivations for truthmaker theory. Moreover, deflationists can consistently articulate and accept such motivations. Deflationism has no bearing on the plausibility of the truthmaker principle.

\footnotetext{
${ }^{6}$ Thanks to Hugh Mellor for helpful comments on several drafts, and to Tim Button for general discussion of the material. This work was supported by a studentship from the Arts and Humanities Research Council.
} 
Keywords

Truthmaking; truthmaker principle; deflationism; MacBride

References

Gupta, A. 1993. A critique of deflationism. Philosophical Topics 21: 57-81.

Horwich, P. 1998. Truth ( $2^{\text {nd }}$ ed.). Oxford: Oxford University Press.

Künne, W. 2003. Conceptions of Truth. Oxford: Oxford University Press.

Lewis, D. 2001. Forget about the 'correspondence theory of truth'. Analysis 61(272): 275-280

MacBride, F. 2013. For keeping truth in truthmaking. Analysis 73: 686-695

Mellor, D.H. 2009. Truthmakers for what? In From Truth to Reality: New Essays in Logic and Metaphysics, ed. H. Dyke, 272-290. London: Routledge.

Rodriguez-Pereyra, G. 2006. Truthmakers. Philosophy Compass 1(2): 186-200.

Simons, P. 2005. Negatives, numbers and necessity: some worries about Armstrong's version of truthmaking. Australasian Journal of Philosophy 83: 253261 